\title{
La moral del sermón de la montaña de Mateo
}

\author{
Xavier Alegre \\ Facultad de Teología de Cataluña, \\ Centro de Reflexión Teológica, San Salvador.
}

\section{Introducción}

Hoy "la moral" tiene mala prensa'. Y es un concepto un poco ambiguo, sobre todo en un mundo postmoderno, en el cual a menudo se entienden cosas distintas cuando se habla de moral. Pero moral tiene que ver con mores, con costumbres, con actuaciones concrelas. $Y$ es innegable que Jesús encarnó y propugnó un determinado "estilo de vida", un modo de obrar que, en un mundo injusto - como era el suyo (iy es el nuestro!)—, lo llevó a una muerte ignominiosa en una cruz. Y si algo parece específico de este Jesús, sorprendente y conflictivo, es precisamente el "sermón de la montan̄a".

Pero aquí aparcce una segunda dilicultad. ¿Tiene sentido hablar de "moral" en relación con el scrmón de la montaña? Pues este sermón parece, de entrada, expresar más bien otra cosa que lo que se suele entender por "moral". Cuando vemos sus exigencias, ¿no pone el listón demasiado alto como para que se pueda hablar de que en él se contiene una "moral" cristiana? De hecho, encontramos en el sermón de la montaña una serie de afirmaciones que resultan "provocadoras" o, al menos, claramente utopicas:

"Dichosos los pobres", "dichosos los perseguidos", "no hagan frente al que les hace mal; al contrario, a quien te abofetea en la mejilla derecha, preséntale también la otra; al que quiera pleitear contigo para quitarte la túnica, dale también el manto".

I. Cfr. R. Rincón Orduria-G. Mora Bartres-E. López Azpitarte. Praxis cristiana, Madrid, $4^{\circ}$ ed. 1986, Vol. I, pp. 225s. En la base de este artículo está una conferencia en la Universidad de Cantabria (Santander), en febrero de 1996. Para profundizar en el significado del sermón de la montaña vale la pena consultar una bibliografía mínima, pero fundamental: J. Zumstein. Mateo el reólogo (C.B. 58), pp. 26-45; U. Luz. EI evangelio segíu san Mateo, Salamanca, 1993, vol. I pp. 257-589; G. Loh/ink, El sermón de la montaĩa, ¿para quién?, Barcelona, 1989; H. Hendrickx, El sermón de la montaña, Madrid, 1986; J. Lambrecht, Pero yo os digo... El sermón programárico de Jesús (Mt 5-7; Lc 6, 20-49). Salamanca, 1994. 
Por ello es obvio que nos hagamos una serie de preguntas al abordar el tema. Por ejemplo, ¿qué consecuencias hay que sacar, tanto a nivel individual como eclesial y social, de estas exigencias tan radicales? ¿Piden una actitud "revolucionaria" frente a la sociedad o, simplemente, una huída "espiritualista" del mundo? En todo caso, ¿cómo hay que interpretar el sermón de la montaña?

Sabemos que todo escrito - y en los evangelios todo fragmento que tiene un carácter propio- tiene sus "reglas de juego", su "forma o género literario". Por eso, si nos cuentan un cuento o una fábula, no nos sorprende que en él aparezca un pequeño príncipe o que los lobos hablen. Pero si un policía, al ponernos una multa, nos hablara de un principito o del hada madrina, más bien nos sorprenderíamos. Como nos sorprenderíamos si el lampista, al mandarnos su factura, jugara con los símbolos numéricos como lo hace el autor del Apocalipsis.

¿Cuál es, pues, la forma literaria del sermón de la montana y qué pistas nos da dicha forma para que lo comprendamos adecuadamente? La respuesta a esta pregunta no parece fácil si miramos la notable diversidad de soluciones que se han propuesto ${ }^{2}$.

Para unos, el sermón de la montaña es tan exigente en lo que pide porque no apunla a que hagamos lo que dice, sino que pretende, tan sólo, que descubramos cuáles son las aclitudes adecuadas que deberíamos tener en la vida (por eso exagera tanto las cosas que ya se ve que no son realizables)".

Para otros, lo único que pretende el autor es que caigamos en la cuenta de lo pecadores que somos (no somos, en absoluto, capaces de hacer el bien, como subrayan determinados intérpretes luteranos) y, por lo tanto, sólo podemos confiar en la misericordia de Dios, que nos salva por puro amor gratuitot.

Para un tercer grupo, en la Iglesia hay que distinguir entre dos grupos de discípulos. Para la mayoría de a pie sólo es necesario cumplir los mandamientos. El sermón de la montaña, en cambio, iría dirigido a una élite (los monjes, por ejemplo), que estaría en lo que se ha denominado un "estado de perfección", por lo que se les puede exigir que cumplan unas normas tan sublimes como las que pide el sermón de la montañas.

Para un cuarto grupo, hay que distinguir entre lo que se le pide al individuo, a título personal, cuando no tiene responsabilidades públicas, y lo que (no) se le puede pedir cuando sí tiene responsabilidades públicas, pues ya se ve que determinadas exigencias del sernón de la montaña serían irrealizables para un político que cumpliera con lo que le pide la "ética de la responsabilidad" y la défensa del bien común frente a los que no se dejan llevar en absoluto por el programa del sermón de la montaña (ni de los mandamientos en general) ${ }^{6}$.

2. Para la historia de la exégesis del sermón de la montaña puede leerse U. Luz, El evangelio según san Mateo, Salamanca, 1993, Vol I. pp. 268-275 con la bibliografía que allí se indica.

3. Pero, entonces, ¿cómo enlaza esto con 7,21 ?

4. Pero, entonces, icómo hay que interpretar Mt 5, 13-16?

5. Pero, entonces, ¿como hay que leer 7, 26-27?

6. Pero nada podemos encontrar en el texto que dé pie a esta interpretación. 
Por último, hay un grupo que sostiene que Jesús es tan exigente en el sermón de la montaña porque creía que estábamos ya en el final del mundo, por lo que propugnaría una "ética provisional" (A. Schweitzer), válida para estas circunstancias excepcionales, pero que, al no cumplirse las expectativas apocalípticas de Jesús, es obvio que habría dejado de tener vigencia ${ }^{7}$.

¿Cómo hay que interprelar, pues, el sermón de la montaña? En todo caso, la interpretación que escojamos ha de hacer justicia al hecho de que nos encontramos aquí con un texto que es fundamental y programático para Mateo.

\section{Importancia del sermón de la montaña}

Todos los comentaristas subrayan el papel que en el evangelio de Mateo desempeñan los cinco grandes discursos que, colocados estratégicamente y con una estructura concéntrica, vertebran, de algún modo, todo el evangelio. Todos ellos son creación del evangelista, quien para ello ha utilizado diferentes materiales que le han llegado de la tradición cristiana que lo ha precedido.

En el caso del sermón de la montaña es clara la labor redaccional de Mateo cuando se compara el material que contiene dicho sermón con los textos paralelos que encontramos en Lucas y que han sido tomados de la fuente $Q^{9}$. Hay un núcleo fundamental común, que encontramos también en Lucas 6, 20-49-es también el sermón inicial de Jesús en Lucas, que Q situaría también a los comienzos de su texto. El resto del material, como puede verse por la comparación de los textos de Mateo y Lucas que presento a continuación, lo ha tomado Mateo de $Q$ y lo ha situado en el sermón de la montaña para que sirva de discurso programático a Jesús. Por ello está muy bien pensado y estructurado por él, y se ha convertido en la presentación clásica del mensaje de Jesús. En cambio, Lucas, que no conoce la versión de Mateo, por un lado, mantiene al

7. Pero textos como Mt 5, 3-10 o 7, 24-25 parecen presuponer que el reino ya se hace aquí y ahora presente.

8. Sobre los autores que proponen una estructura de Mateo basada en los cinco discursos fundamentales (Mt 5-7: sermón de la montaña; 10: sermón de misión; 13, 1-52: sermón de las parábolas; 18: sermón eclesial; 24-25 [pienso que el cap. 23 no forma parte de este discurso]: sermón escatológico), puede consultarse R. Aguirte. en R. Aguirre y A. Rodríguez, Evangelios sinópticos y Hechos de los Apóstoles, Estella, 1994, pp. 222-225.

9. Si comparamos los textos paralelos de Mateo y Lucas -en la columna izquierda del cuadro "Trasfondo del sermón de la montaña", que viene a continuación, están colocados los textos del primero y sus equivalentes en Lucas (cuando los textos no se encuentran en Lucas, dejamos el espacio en blanco)- podemos ver con toda claridad, no sólo las semejanzas en el núcleo entre ambos discursos, sino tambiên en qué medida Mateo cambió el orden de algunos textos (véase Mt 7,12 con el par. Lc 6, 31) y añadió, por un lado, varios textos que se encontraban en otros lugares de la fuente $Q$ (y que Lucas colocó en el "camino a Jerusalén") y, por otro, material propio de él.

Sobre el significado de los discuros en Mateo, cfr. R. Aguirre, Evangelio según san Mateo, en R. Aguirte y A. Rodríguez, Evangelios sinópticos y Hechos de los ApósIoles, Estella, 1992, pp. 199s, 222-225. 
inicio de su obra, como sermón de la llanura ( $L c$ 6, 20-49), lo que constituía el sermón inicial en $\mathrm{Q}$. Pero, por otro, pone el resto de palabras de $\mathrm{Q}$ que Mateo ha situado en el sermón de la montaña, en diversos lugares de su evangelio, fundamentalmente en el viaje a Jerusalén, pues suele aprovechar el material de Q. para dar mayor cuerpo a dicho viaje, que es una parte importante de su obra (de Marcos sólo puede aprovechar un capítulo para dicho viaje a Jerusalén).

\section{Trasfondo del sermón de la montaña ${ }^{10}$}

(Lucas)

6. $20 ; \mathrm{cfr} .6,17$

6, 20-23

$14,34 s ; 11,33 ; 8,16$

16,17

$(12,58 s)$

(cfr. 16, 18/ como Mc 10 ,

lis/Mt 19,9$)$

$6,29 s$

$6,27 \mathrm{~s} .32-35$

6,36

$11,2-4$

$12,33 \mathrm{~s}$

$11,34-36$

16,13

$12,22-31$

6. $37 \mathrm{~s} .41 \mathrm{~s}$

$11,9-13$

6,31

$13,23 \mathrm{~s}$

$6,43-45$

6,$46 ;(13,26 s)$

$6,47-49$

\section{Mateo}

$5,1-2$

$5,3-48$

5, 3-10

5, 13-16

$5,17-20$

$5,21-48$

- 5, 21s. (23-26)

- 5, 27s. (29s)

- 5, $31 \mathrm{~s}$

- 5, 33-37

- 5, 38-42

- 5, 43-47

5,48

$6,1-7,12$

6, I

$6,2-4$

6, 5-6

$6,7-8$

6. $9-13$

$6,14-15$

$6,16-18$

$6,19-21$

$6,22-23$

6,24

$6,25-34$

$7,1-5$

7,6

$7,7-11$

7,12

7, 13-27

$7,13-14$

7,15

$7,16-20$

7, 21-23

7, 24-27
Introducción

Bloque A

Bienaventuranzas

Sal de la tierra.

Luz del mundo

Validez de la Ley

6 antítesis

- Ira (reconciliar)

- Adulterio

- Repudio

- Juramento

- Venganza

- Amor a enemigos

Sed perfectos

\section{Bloque B}

Piedad (justicia)

Limosna (v.4!)

Oración (v.6!)

Orar (palabrería)

PADRE NUESTRO

Perdonar

Ayuno (v. 18!)

No atesorar

Parábola del ojo

No servir dinero

No agobiarse

No juzgar

No dar a "perros"

Confianza oración

Regla de oro

\section{Bloque C}

Puerta estrecha

Falsos profetas

Conocer por frutos

Falsa piedad

Parábola dos cases

\section{7, 1; 4, 32/Mc 1, 22}

$7,28 \mathrm{~s}$

Conclusión

10. Los únicos textos del "sermón del llano" que no se encuentran en Mateo son Lc 6, 24-26 (imprecaciones) y 6, 39-40 (parábola del ciego que gufa a otro ciego). 


\section{Significado del sermón de la montaña}

El primero de estos discursos construidos por Mateo, y situado estratégicamente en su evangelio, es el denominado sermón de la montaña (Mt 5-7). Por su colocación al inicio de la presentación del programa de Jesús, dicho discurso adquiere, sin duda, el carácler de discurso programático". ¿Qué quiere decirnos, pues, con dicho discurso Mateo?

Se ha presentado, con razón, este sermón como "la proclamación del reino y de la enseñanza moral que posibilita y exige" (R. Aguirre). Según este autor'?:

la enseñanza ética de Jesús, presentada a continuación en el sermón de la montaña, contiene, de hecho, exigencias, pero ante todo, expresa las nuevas posibilidades abiertas por la presencia del reino.

Y según J. Lambrecht ${ }^{13}$ :

Jesús traía una buena nueva en nombre de Dios y llamaba a los hombres a darle una respuesta. Estos dos aspectos, mensaje y llamada, anuncio y exhortación, están eminentemente presentes en el sermón programático de Jesús.

Se nos da entonces la posibilidad de escuchar todos la palabra delinitiva de Dios y de ponerla en práctica.

Para comprender mejor el mensaje que Mateo quicre comunicarnos en el sermón de la montaña, voy a desarrollar sobre todo dos aspectos. En primer lugar, la situación eclesial de Mateo, a la cual quiere responder el autor y, en segundo lugar, la estructura que Mateo da al sermón de la montaña.

\section{El contexto eclesial de Mateo}

\subsection{La fidelidad al Antiguo Testamento}

Una de las preocupaciones que configura la manera cómo Mateo formula su evangelio es el de la relación entre el Antiguo Testamento y el mensaje de Jesús (una cuestión agudizada en la comunidad de Mateo por la negación de la comunidad judía, en su conjunto, a aceptar a Jesús y por las relaciones entre el judeocristianismo y el paganocristianismo, que en muchas comunidades - pienso sobre todo en las de origen paulino- resultaron difíciles). Pues bien, el evangelio de Mateo representa la postura de la Iglesia de Antioquí, marcada por la figura de Pedro, en un momento decisivo de su existencia ${ }^{14}$. Se trata de

11. Además, si se compara el inicio de Mareos con el de Mateo llama la atención que mientras aquél presenta a Jesús con un bloque de acciones milagrosas ( $c f r$. 1. 2I45), en las cuales manifiesta su autoridad/poder (y sólo más tarde, en 4, I-34, nos da los contenidos de su enseñanza), éste, en cambio, presenta a Jesús como el maestro de la "justicia mejor" en el sermón de la montaña y sólo después presenta sus milagros, que así son subordinados a su enseñanza (P. Hoffmann, "Die Stellung der Bergpredigt im Matthäusevangelium", Bibel und Leben 10 (1969) p. 59).

12. "Composición y trama del evangelio de Mateo", Reseña Bíblica, № 2 (1994), p. 8.

13. Pero yo os digo, p. 11.

14. Esto se deduce del conflicto teológico eclesial entre Pedro y Pablo, que éste nos narra en Gal 2,11-14, que se zanjo al inclinarse la comunidad de Antioquía por la 
una comunidad judeocristiana abierta claramente a los paganos, que podían formar parte de la comunidad sin necesidad de ser judíos. Pero es una comunidad que, a la vez, se esfuerza por mantener los lazos con la Iglesia más conservadora de Jerusalén y con el judaísmo en general. Por ello, el evangelista tiene interés por mostrar las raíces judias de la fe cristiana y la fidelidad de la misma a la voluntad de Dios, expresada en el Antiguo Testamento". A esa finalidad se debe que Jesús, según Mateo 5, 17-19, subraye que ha venido a cumplir radicalmente la ley y los profetas y no a abolir ni siquiera la letra más pequeña de ella.

Pero, a la vez, y para evitar una comprensión fundamentalista del Antiguo Testamento, Mateo tiene interés en ofrecer la interpretación auténtica y viva que hizo Jesús del Antiguo Testamento. Esta interpretación ha llegado a la comunidad a través de Pedro, que es el garante de la interpretación adecuada de Jesús ${ }^{\prime \prime}$. $\mathrm{Y}$ a esa interpretación nueva no se puede renunciar en absoluto (es el vino nuevo que no debe echarse en odres viejos: $c f r$. MI 9, 17) si se quiere ser fiel seguidor de Jesús, el auténtico intérprete de la voluntad de Dios, concretada en la ley y los profetas. Por ello, Mateo añade en 5, 20:

Porque les digo que, si su justicia no es mayor que la de los escribas y fariseos, no entrarán en el reino de los cielos.

Todo el evangelio, pero de un modo particular el sermón de la montaña, intenta explicitar en qué consiste esta "justicia mayor" o modo radical de cumplir la voluntad de Dios: en un fiel seguimiento de Jesús, tal como el resucitado había encargado a los once, al aparecérseles en una montaña de Galilea ( $c f r$. Mt 28, 19).

En la misma línea de continuidad (discontinua, pero fiel) con el Antiguo Testamento se encuentran las repetidas constataciones de Mateo a propósito de la concordancia entre Jesús y la ley y los profetas: todas ellas subrayan que Jesús, en sus palabras y obras, es el cumplimiento auténtico del Antiguo Testamento (cfr. Mi 1, 22s; 2, 5s. 15.17s23; 4, 12-16, etc.).

\subsection{El amor al prójimo, criterio decisivo}

Pero hay también otra cuestión comunitaria que preocupó mucho a Mateo, que encuentra su reflejo en el sermón de la montaña. Es la existencia de grupos más bicn carismáticos - y muy influyentes en la comunidad-, que se preocupaban poco de cumplir la ley fundamental del amor al prójimo y despreciaban a otros grupos que. a su juicio, cran menos significativos dentro de la comunidad.

postura más contemporizadora con el judaísmo de Pedro y no con la más radical de Publo. Esto motivó que Pablo dejara Antioquía y se dedicara, a partir de aquel momento. a la fundación de comunidades de clara orientación pagano cristiana. Sobre la comunidad de Maleo y la Iglesia de Antioquia, cfr. Aguirre, Evangelios. pp. 262-267, 27I-275.

15. Sobre las relaciones entre Israel y la Iglesia cristiana, cfr. Aguirre, Evangelios, pp. 231-235.

16. Sobre el papel de Pedro en Maleo, cfr. Aguirre, Evangelios, pp. 244-247. 
El talante de los grupos carismáticos, en unos tiempos en los cuales Mateo subraya (iy es un texto propio de él!) que "se enfriará el amor de la mayoría" $(24,12)$, aparece muy claramente en un texto del sermón de la montaña. Hacia el final del mismo dice Jesús:

No todo el que me dice: ;Señor, Señor! entrará en el reino de los cielos, sino el que hace la voluntad de mi Padre que está en los cielos. Muchos me dirán aquel día: - ¡Señor, Señor!, ¿no profetizamos en tu nombre, y en tu nombre expulsamos demonios, y en tu nombre hicimos muchos milagros? Pero yo les responderé: No les conozco: ¡apártense de mí, malvados! (7, 21-23).

Por lo visto, en la comunidad de Mateo hay un grupo significativo de cristianos y cristianas que se enorgullece de su capacidad para realizar milagros y profetizar. Y Mateo no niega que esto sea verdad. Pero esto no les lleva, en opinión del evangelista, a cumplir la voluntad de Dios que para él se concreta. como veremos (cfr. Mt 7,12), en el amor radical al prójimo. Lo que aqu he traducido, siguiendo la versión de la Casa de la Biblia, como "malvados" es la traducción de una expresión griega que, literalmente, podríamos traducir como "ustedes que obran la iniquidad" (ergazomenoi tên anomian), es decir, los que no cumplen la voluntad de Dios.

$\mathrm{Y}$ el poco aprecio de los pequeños (se refiere a aquellas personas de la comunidad que eran menospreciadas por los que se creían superiores) por parte de este grupo, de talante más bien carismático, aparece en la formulación que da Mateo a la parábola del buen pastor (actualizando el texto, probablemente más original, más jesuánico de Lc 15, 3-7):

Cuidado con despreciar a uno de estos pequeños ${ }^{17}$, porque les digo que sus ángeles en el cielo contemplan sin cesar el rostro de mi Padre celestial. ¿Qué les parece? Si un hombre tiene cien ovejas y se le extravía una de ellas, ¿no dejará en el monte las noventa y nueve e irá a buscar la descarriada? Y si llega a encontrarla, les aseguro que se alegrará por ella más que por las noventa y nueve que no se perdieron. Del mismo modo su Padre celestial no quiere que se pierda ni uno solo de estos pequeños (Mt 18,10-14).

Para corregir estas tendencias equivocadas de miembros probablemente significativos de su comunidad, Mateo, siguiendo el ejemplo de Marcos, recupera la figura de Jesús, su manera de actuar y sus enseñanzas y las coloca en el contexto de su vida concreta, que lo llevó a la cruz y a la resurrección. Pero mientras Marcos se esfuerza por corregir las tendencias triunfalistas de su comunidad'", Mateo, además de poner de manifiesto la continuidad con el Antiguo

17. Lc 15, 3-7 no habla de pequeños. sino de pecadores, de acuerdo con el contexto en el cual coloca la parábola: $c f r$. Lc $15,1-2$. En cambio. Mt sitúa la parábola en el contexto del denominado "sermón eclesial" (Mt 18), en el cual procura resolver problemas eclesiales de su comunidad con ayuda de la palabra de Jesús.

18. Cfr. X. Alegre. "Marcos o la corrección de una ideología triunfalista. Para una lectura de un evangelio beligerante y comprometido", Revisfa Latinoamericana de Teología 2 (1985), pp. 229-263. 
Testamento, subraya en qué medida la vida y enseñanza de Jesús muestran que la voluntad expresa de Dios se concreta en la radicalización del amor al prójimo, pues en este precepto, interpretado y vivido a la manera de Jesús, llega a su plenitud la voluntad de Dios revelada en la ley y los profetas.

Varios textos de Mateo confirman esta tesis. En primer lugar, el texto clave con el cual concluye el evangelio y que al evangelista le sirve para poner de manifiesto que, después de pascua, sigue vigente todo lo que enseñó a cumplir Jesús de Nazarel. Me refiero a Mateo 28, 16-20.

No es casual en la intención teológica de Mateo que esta aparición esté ubicada en una montaña de Galilea $(28,16)$, haciendo así inclusión con la montaña de Galilea en la cual, según él, Jesús habla pronunciado su discurso programático (cfr. 5, 1ss en el contexto de 4, 23). La tentación del grupo carismático parece encontrarse en el hecho de que no tomaban en serio la voluntad de Dios expresada en la ley, con la excusa que, después de pascua, Dios esperaba otro cumplimiento "más sublime" de su voluntad que el concretado en aquélla. Por eso, el resucitado insistirá, al enviar ahora a sus discípulos a la misión entre los paganos, que deben hacerlo "convirtiendo en discípulos (de Jesús) a todos los pueblos de la tierra" (28, 19a). Y ello lo lograrán, por un lado, con un rito de iniciación, el bautismo, que simboliza el modo nuevo de la filliación divina propia de los miembros de la comunidad $(28,19 b)$. Y, por otro, "enseñándoles a poner por obra - según palabras del resucitado- todo lo que yo les he mandado" $(28,20 a)$. En este contexto, pues, Jesús resucitado sanciona la enseñanza fundamental realizada por Jesús de Nazaret, en su vida terrena (¡no manipulable!), que Mateo presentó programáticamente al comienzo del evangelio en el sermón de la montaña ${ }^{19}$. A la vez, si el resucitado recuerda a sus discípulos no sólo lo que él ha "dicho", sino lo que él ha "mandado", ello significa que Mateo entiende "la palabra de Jesús como mandamiento en el sentido de una nueva interprelación de la ley"'no. Por ello, Hoffmann" ha señalado que a partir de 28,19 se confirma la impresión de que "el discurso de Jesús en el sermón de la montaña es el centro oculto del evangelio de Mateo. Es, por así decirlo, el canon en el canon, el evangelio en el evangelio".

En el fondo, loda la obra de Mateo es una escuela de discernimiento de lo que Dios realmente quiere y espera de los creyentes. Pues en el entorno en el cual apareció su evangelio se encuentran enfrentadas dos maneras contrapuestas de interpretar la voluntad de Dios, que ha sido revelada en la ley y los profetas (cfr. 5, 17-20): la de los escribas y fariseos de religión judía y la de los cristia-

19. "En otras palabras, el resucitado hace normativa para la Iglesia de todos los tiempos y hasta el fin del mundo la palabra del Jesús terreno. El mensaje del resucitado es idéntico al del Jesús terreno. El señor del universo se da a conocer sola y exclusivamente a travês del mensaje proclamado por el hombre Jesús" (J. Zumstein, Mateo el teólogo, Estella, 1987, p. 30).

20. Hoffmann, op. cit., p. 64.

21. Ibid., p. 65 . 
nos y cristianas. Para Mateo sigue siendo válido que la quintaesencia de la voluntad de Dios queda concretada en la ley y los profetas:

No piensen que he venido a abolir las enseñanzas de la ley y los profetas; no he venido a abolirlas, sino a llevarlas hasta sus últimas consecuencias. Porque les aseguro que mientras duren el cielo y la tierra, la más pequeña letra de la ley estará vigente hasta que todo se cumpla. Asf que el que descuide uno de estos mandamientos más pequeños y enseñe a hacer lo mismo a los demás, será el más pequeño en el reino de los cielos. Pero el que los cumpla y enseñe, será grande en el reino de los cielos (cfr. 5, 17-19).

El problema radica para él en que no es fácil saber cómo hay que interpretar y actualizar esta voluntad de Dios, que se expresaba en el Antiguo Testamento. Pues no se trata de un cumplimiento al pie de la letra (hoy diríamos "fundamentalista"), como él cree que lo hacen los escribas y fariseos que no se han abierto al mensaje de Jesús ( $c f r .5,20$ : "Les aseguro que si su justicia no es mejor que la de los escribas y fariseos, no entrarán en el reino de los cielos"), sino de un cumplimiento que quede iluminado por la praxis de Jesús y por su enseñanza, tal como él los narra en su evangelio. Pues para él,

todo maestro de la ley que se ha hecho discípulo del reino de los cielos, es como el amo de casa que saca de su tesoro cosas nuevas y viejas $(13,52)$.

Por eso, la primera palabra de Jesús que Mateo recoge en su obra es aquella en la cual Jesús dice a Juan Bautista, cuando éste no se considera digno de bautizar a Jesús, que es necesario, en el plan salvífico de Dios, que ambos cumplan la voluntad de Dios: "Deja ahora: porque conviene que de este modo cumplamos lo que Dios ha dispuesto" $(3,17)$.

Propiamente, el texto habla, utilizando una palabra muy significativa para Mateo, de que "nos conviene cumplir toda justicia". Para Mateo la "justicia" consiste en hacer la voluntad de Dios. Pero, entonces, la pregunta es ¿qué quiere Dios de nosotros? Para Mateo, la parábola última del "juicio final" (cfr. 25, 3146), con la cual ilumina qué es lo que Dios examinará en nosotros "en el alardecer de nuestra vida", recoge muy bien en qué consiste fundamentalmente esta voluntad de Dios. No nos preguntará si hemos cumplido al pie de la letra -como procuraban hacerlo, según Mateo, los escribas y lariseos judíos- todas y cada una de las leyes que encontramos en el Antiguo Testamento. Nos preguntará, más bien, si hemos cumplido el precepto del "amor radical al prójimo", sobre todo al "prójimo necesitado" (el "hermano más pequeño" de Jesús, con el cual Jesús se ha identificado: ver $25,40.45$ ), tal como lo expresa la parábola de 31-46:

tuve hambre, y me dieron de comer; luve sed, y me dieron de beber; era forastero, y me alojaron; estaba desnudo, y me vistieron; enfermo y me visitaron; en la cárcel, y fueron a verme" $(25,35-36)$.

Por eso, Zumstein ${ }^{22}$, al examinar cómo interpreta Jesús la ley, propone la lesis de que "la ética se convierte en el único camino que conduce a la aproba-

22. Op. cit., p. 33. 
ción divina". Porque en el amor al prójimo se encierran, como en su quintaesencia, la ley y los profetas ( $c f r .7,12$ y 22, 40). Y el amor al prójimo nos da la clave para discernir, en caso de conflicto de valores (por ejemplo, entre los valores específicamente religiosos y los éticos: cfr. 12, 1-14), por dónde se decanta lo que Dios, en estos casos, espera de nosotros. Pues para Dios, como subraya Jesús en 9,13 y 12,7 (citando a Os 6,6 ), es más importante la misericordia que el sacrificio. Por eso, a los maesiros de la ley y a los fariseos los tacha de hipócritas, porque, les dice Jesús

pagan el diezmo de la menta, del anís y del comino, y descuidan lo más importante de la ley: ¡la justicia, la misericordia y la fe! Hay que hacer esto, sin descuidar aquello. ¡Guías ciegos, que cuelan el mosquito y se tragan el camello! $(23,23)$.

\section{La estructura del sermón de la montaña}

Dado que el sermón de la montaña no es, sin más, un discurso del propio Jesús, sino una creación del teólogo Mateo, aprovechando, sin duda, material que se remonta a Jesús, no podemos interpretar los textos al margen de su contexto ( $i$ los convertirfamos en prelexto!). Por eso es importante que intentemos descubrir la estructura del sennón de la montaña ${ }^{23}$ e interpretemos los textos a la luz de todo el evangelio, teniendo en cuenta lo que hemos averiguado sobre la comunidad del evangelista.

\section{Estructura del sermón de la montaña}
A. 5, 1-2
Convocación de los oyentes
B. 5, 3-16
Introducción
a. 5, 3-10 ( $3^{2}$ pers. $)$
Bienaventuranzas (reino: $2 x$ )
b. 5,11 s. $13-16\left(2^{2}\right.$ p. $)$
C. $5,17-7,12$
c. $5,17-20$
d. $5,21-48$
e. $6,1.2-4$
Persecuciones + sal, luz
Parte principal
Introducción (ley + profetas)
Antítesis (identidad crist.)
Justicia ante Dios (limosna)
i. $5.9 .13 .14 \mathrm{~s}$
Justicia ante Dios (oración)

23. La propuesta de U. Luz en El evangelio según San Maseo, Salamanca 1993, vol. 1. p. 259-261. presentando una estructura concéntrica del sermón de la montaña me parece muy iluminadora. En dicha propuesta el Padrenuestro constiluye el corazón del sermón de la moniaña y queda enmarcado por el resto del sermón. Por un lado. la oración se encuentra entre la limosna y el ayuno. Y por otro, el mismo Padrenuestro está enmarcado por las exigencias de no orar con palabrería $(6,7-8)$ y perdonar (6, 14-15). 
e'. $6,16-18$

d'. $6,19-7,11$

c'. 7,12

B'. 7, 13-27

b'. 7, 13-20 (2 pers.)

a'. 7, $21-27$ ( $3^{2}$ pers.)
Justicia ante Dios (ayuno)

Valores (identidad crist.)

Conclusión (ley + profetas)

\section{Conclusión}

Camino que lleva a la vida

En el reino se entra por la praxis

(reino: $2 x$ )

Reacción de los oyentes

\subsection{Significado de la introducción (5, 3-16)}

El sermón de la montaña empieza con la proclamación de unas bienaventuranzas que, en principio y de acuerdo con lo que debió ser la proclainación de Jesús que recogió la fuente $Q$ (cfr. los textos paralelos de Lc 6, 2023), no expresan una "bienaventuranza" que resulte obvia en el marco de una ética determinada. Este sería el caso de la bienaventuranza del Salmo 1, 1-2:

Dichoso el hombre que no sigue el consejo de los impios; ni entra por la senda de los pecadores, ni se sienta en la reunión de los cínicos, sino que su gozo es la ley del Señor, y medita su ley día y noche ${ }^{24}$.

Se trata, inás bien, de un don de Dios que se hace presente en la actuación de Jesús ${ }^{25}$. Pues al margen de la buena noticia que en Jesús de Nazaret Dios está cumpliendo su promesa (cfr. Is $61,1-2$ ) en favor de los pobres y marginados,

Lo mismo ocurre con el resı del sermón de la montaña, como indican las letras de la parte izquierda de la estruclura. A las antítesis que encontramos en 5, 21-48, que expresan unos valores que son propios de la identidad cristiana, que lleva a su plenitud, desde Jesús, el Antiguo Testamento, corresponden, en la parte inferior, los valores cristianos que enconiramos en $6,19-7,11$. Los valores que se piden aquf son no poner el corazón en las riquezas $(6,19-24)$, no agobiarse $(6,25-34)$, no juzgar $(7,1-5)$, no dar lo santo a los pertos $(7,6)$ y confianza en la oración $(7,7$ 11).

24. Cfrr. tambiên Sir 25, 7-11: "Dichoso el que se alegra con sus hijos, el que no tiene que servir a un inferior; dichoso el marido de mujer sensala, el que no tiene que arar con buey y asno; dichoso el que vive para ver la derrota de sus rivales, y.el que no resbala con la lengua; dichoso el que encuentra un amigo, y el que no habla a oídos sordos; grande es el que alcanza la sabidurfa, y nadie como el que teme al Señor".

25. Como observa J. M. Castillo, Teología para comunidades, Madrid, 1990, p. 119s: "lo primero que aparece en este programa (se refiere a las bienaventuranzas de Mateo) es que Jesús promete a sus discipulos la felicidad. Una felicidad que no proviene de los valores que el mundo considera necesarios para ser feliz, sino exactamente de todo lo contrario. Por consiguiente, el programa del grupo cristiano comporta una transmutación de los valores. La tarea de Jesús se encamina, ante todo y sobre todo, a rehacer al hombre, devolviéndole la dicha y la paz". 
las bienaventuranzas son una paradoja. que sólo resultan de algún modo comprensibles desde el horizonte de la fe bíblica. Pues no se las comprendería bien si se las interpretara sólo como una palabra de consuelo dirigida a los pobres, los tristes, los hambrientos o los perseguidos. Porque pretenden ser una "proclamación del nuevo orden de Dios ante la opinión pública del mundo"zo. Sólo en el contexto del reino, que con la venida de Jesús ha empezado a hacerse presente en el mundo (cfr. 4,$23 ; 12,28$ ), tienen sentido las bienaventuranzas. Pues en el contexto del Antiguo Testamento, en el cual aparece claramente la opción de Dios por los pobres y marginados, si Dios reina, ello implica que Dios, que es el único "señor" de la tierra (cfr. Lv 25, 23), toma el partido de los pobres y, a través de la comunidad de la alianza ${ }^{27}$, consigue que los derechos del pobre y del marginado, de la viuda y del extranjero sean respelados, de modo que la pobreza y la injusticia, la violencia y el sufrimiento sean erradicados (cfr. Dt 15, 4 en el marco de 15, 1-11; Lv 25, I-19; Ecl 35, 14-22; 1s 58, 1-12; tambjén Ex 21,2-11;22, 24; 23, 6.10-11 etc.). Como nola Lambrecht ${ }^{2 n}$.

aunque no se diga expresamente, no están ausentes el trasfondo cristológico y la historia de la salvación. Porque la actividad de Jesús en aquella Galilea $y$ en aquel tiempo concreto es lo único que hizo posible las bienaventuranzas. El mismo Cristo forma parte del cumplimiento de las promesas. Es con su omnipotencia, en cuanto enviado de Dios, como proclama las bienaventuranzas. Lo que se nos anuncia a todos, hombres pobres y que sufren, es la salvación divina, inmerecida, gratuita.

El macarismo es en sí mismo un evangelio, una alegre nolicia, una primera aplicación concreta de la predicación, que anuncia que el reino está ya próximo. Y como esta proximidad de Dios está ligada efectivamete al hecho de que Jesús entra ahora en escena, estos macarismos son también cristológicos, aunque más discreta y menos directamente que la bienaventuranza siguiente de los perseguidos ${ }^{24}$.

Mateo, evidentemente, no niega este presupuesto teológico del sermón de la montaña que lorma partc de la buena noticia del reino que Jesús anunciaba ( $c f r$. $4,23$ y 9,35$)$ y que es condición de posibilidad del estilo de vida que él, en nombre de Jesús, pide a su comunidad. Pero la situación que vive su comunidad

26. P. Holfmann, "'Selig sind die Amnen...' Auslegung der Bergpredigl II (Mt 5. 316s)". Bibel und Leben 10 (1969) p. 117.

27. Sobre el sentido de la elección en la Biblia, cfr. A. Wénin. "Israel, extranjero y emigrante. El tema de la inmigración en la Biblia". Selecciones de Teologia 35 (1996) pp. 247-256.

28. Op. cir, p. 56. Y añade ibid. pp. 56s: "Trilling llama a esta predicación inaugural de Jesús promesa incondicionada de salvación, revelación de Dios en el tiempo". P. Hoffmann delíne las bienaventuranzas como proclamación pública del nuevo orden de Dios ante la faz del mundo. En cuanto a J. Dupont repite continuamente esta idea en sus publicaciones: "Las bienaventuranzas son. ante todo, una revelación sobre la misericordia y la justicia que han de caracterizar al reino de Dios".

29. Cita G. Shreiner, Die acht Zaligheden, p. 277. 
es distinta de la que vivió Jesús en sus inicios y ello lo lleva a actualizar el mensaje. Pues en su comunidad hay ahora cizaña junto al trigo (cfr. 24-30.3643). peces malos junto a peces buenos ( $c f r .13,47-50$ ), personas que formando parte de la comunidad "no Ilevan el vestido nupcial" (cfr. 22, 11-14) o buscan determinados privilegios que Jesús quiso excluir de su comunidad (cfr. 23, I12). Hay personas que marginan a los "pequeños" (cfr. 18, 1-14) y son incapaces de perdonar ( $c f r .18,15-35)$ o, como mínimo, son "de poca fe" ( $c f r .8,26$; $16,8)$. Por ello adapta las bienaventuranzas de Jesús a la situación eclesial de su comunidad, de modo que ahora, en su versión, incorporen también un elemento ético: si la liberación de Israel de la opresión egipcia era el regalo de Dios que fundamentaba la alianza del Sinaí y quedaba concrelada en los diez mandamientos, ahora las bienaventuranzas son el regalo de Dios que fundamenta la nueva alianza y que queda concretado en las exigencias del sermón de la montaña. Pues si hay pobres, esto es señal de que la justicia de Dios no ha conseguido triunfar en la tierra, por lo que el creyente es invitado, ahora, a tener hambre y sed de justicia y a irabajar por ella, aunque esto implique la persecución. Es, pues, en el contexto eclesial de Mateo que se comprende el hecho de que acentúe

las disposiciones interiores. Algunas expresiones como "de espíritu", "de corazón", "tener sed de justicia", "mansos" y "misericordiosos" no designan en primer lugar un grupo social, sino una disposición de alma, un estado de espíritu particular, una orientación de vida que seguir, una disposición mora] ${ }^{10}$.

30. Lambrecht op. cir., pp. $61 \mathrm{~s}$. Es en este contexto que hay que interpretar el añadido a la primera bienaventuranza (la Casa de la Biblia traduce: "pobres en el espiritu"), que I. Ellacuria traducía, acertadamente, "pobres con espíitu”. Según Hoffmann (ibid.) los paralelos de Qumrán facilitan la interpretación de esta fórmula difícil. Su formulación se remonta. probablemente, al texto de Is 66, 2 donde se habla del "humilde y contrito" ("any wnkeh ruaj). "Pobre en el espíritu" describe aqui la exigencia de confiar en Dios y de la "humildad", tal como ya pronto se relaciono con el concepto veterotestamentario de pobreza. En Qumrán la fómula la utilizan los miembros de la secta para autodenominarse y expresa la observancia de la secta. También en Mateo tiene la iórmula contenido religioso, pero con un cuño típicamente cristiano. El discípulo debe serguir con esta pobreza al mesías Jesús, el cual, según Mt 11, 28-30, invita, como "humilde de corazón" (sapeinos tê kardia), al seguimiento. De modo perspicaz se subraya, al comienzo de las bienaventuranzas. que esta nueva actitud de piedad ha de configurar al discipulo "en el espíritu", es decir, en lo más profundo de su ser (¡no sólo exteriormente!). Un sentido semejante es el que tiene el añadido "en el corazón" en la bienaventuranza de los "limpios", sobre todo si se la incerpreta a la luz de la controversia sobre lo puro y lo impuro que encontramos en Mt 15, I-20: lo que vuelve impuro es el pecado que brota del corazón (cfr. 5, 18-19); una "pureza" meramente exterior (cfr. 23, 28) no interesa en absoluto.

Esta interpretación me parece mejor que la que proponen J. Mateos-F. Camacho, El evangelio de Mateo. Lectura comeniada, p. 53, cuando comentan: "El sentido de la bienaventuranza es. por tanto, los 'pobres por decisión', oponiéndolos a los 'pobres 
Conviene, pues, tener presente que "las bienaventuranzas de Mateo, considerando a la vez el primero y el segundo miembro, no son, como las tres bienaventuranzas de $\mathrm{Q}$, ante todo una proclamación; se han convertido también - y de modo ahora significativo- en exhortación, en amonestación, en exigencia ética. Desde esta perspectiva, la dimensión del compromiso por una vida religiosa y moral pasa a primer plano. El don de Jesús para todos pasa a ser, en Mateo, tarea de los cristianos"'". Con ello Mateo quiere evitar que su comunidad, ingenuamente, se crea ya en consonancia con el reino. Por ello reformula los textos de la tradición de modo que en ellos se iransparente, junto con la promesa, la exigencia que plantea Jesús a la comunidad del evangelista ${ }^{32}$. En este sentido, mientras las bienaventuranzas quedan enmarcadas, por un lado, por la promesa del reino (cfr. 5, 3.10), por otro señalan también en dos lugares clave (en la segunda y en la cuarta bienaventuranza: $c f r .5,6.10$ ) la intención fundamental que Mateo ha tenido al reelaborar las bienaventuranzas: la justicia". Pues

por necesidad'. Es la interpretación que Jesús mismo propone en 6.24 , la opción entre dos señores, Dios y el dinero" (citado por J. L. Sicre, "Temas selectos del primer evangelio (Ili) el sermón del monte". Proyección 38 (1991) p. 267. Pues en esta traducción (o en la correspondiente "los que eligen ser pobres") no aparece adecuadamente el elemento primordial jesuánico, que Mi aclualiza, pero no cuestiona, de lo que significa para los pobres la venida de Jesús (cfr. Mı 11, 2-5). Y, como nota Luz, op. cit., I, p. 287, n. 46. "la idea de pobreza voluntaria se expresarín de otro modo, tanlo en griego como en hebreo arameo".

Sobre las distintas interpretaciones del añadido de Mt, puede verse Luz, op. cis., pp. 287-290. Para él, ibid., p. 289. "la pobreza social pasa a segundo plano y la miseria psiquica pasa a ocupar el primero. Esta apunta a la actitud ética de humildad. Hay que hablar, pues, de una tendencia a la interiorización y a la etización de la primera bienaventuranza. No es posible precisar claramente qué postura adopta el evangelista. La expresión 'pobre de espíritu' no permite decidir si los humildes son pobres o ricos".

31. Lid., p. 63. F. Camacho lo formula asi: "las bienaventuranzas evangélicas proponen los principios fundamentales por los que ha de regirse la conducta humana que quiera situarse bajo la soberanía de Dios, es decir, que quiera formar parte de la sociedad y de la humanidad nuevas que crea el reino o reinado de Dios. Las bienaventuranzas, por tanto, generan una ética, la propia de los que tienen a Dios por rey 0 , si se prefiere, siguiendo la disyuntiva que el inismo Mt plantea en el sermón de la montaña, la de aquellos que sirven a los intereses de Dios y no a los del dinero (Mt 6,24)", "Etica, utopía y bienaventuranzas". en Etica universal y cristianismo, Madrid, 1993, p. 117.

32. Así Hoffmann. Selig, p. 118.

33. Como señala también, ibid., "las distintas bienaventuranzas sirven para ilustrar los rasgos esenciales del discipulado, que $M t$ en otro lugar describe, acertadamente, como bondad y fidelidad a las exigencias de Dios $(23,23)$. El modo de obrar del discípulo se ha de apoyar - a diferencia de la hipocresfa farisea- en la globalidad de la persona; lo que Dios le pide le ha de configurar hasia lo más profundo de su ser. Como ejemplo de discipulado verdadero se encuentra, detrás de las formulaciones, el ejemplo dol Mesías Jesús, bondadoso y obediente. En las distintas 
los criterios para saber si uno es un verdadero discípulo de Jesús vienen dados por la justicia, la misericordia y el amor al prójimo ${ }^{34}$, sabiendo que "justicia", como señala Zumstein"s., "es, por excelencia, la noción que utiliza Mateo para expresar el comportamiento fiel a la voluntad de Dios" (aparece en siete ocasiones: 3,$15 ; 5,6.10 .20 ; 6,1.33 ; 21,32) " .16$.

Por otro lado, con las bienaventuranzas, Mateo sitúa la ética cristiana en el horizonte de su cristología. Pues como nota Lambrecht ${ }^{37}$.

En este texto el Jesús mateano traza de algún modo su propio retrato. El es el paradigna, el gran ejemplo; él realizará totalmente este programa "cristiano". El Jesús maleano es todo lo que describen las bienaventuranzas. Bástenos cilar algunos textos: "Es él quien tomó nuestras enfermedades y cargó con nuestras debilidades" (8, 17); "Vengan a mí todos los que están cargados y yo los aliviaré. Tomen sobre ustedes mi yugo y aprendan de mí, que soy manso y humilde de corazón, y encontramán descanso para sus almas. Mi yugo es llevadero y mi carga ligera" (II, $\overline{28}-30)$; "he aquí -dice Dios- mi sicrvo al que he elegido y mi amado en quien me he complacido; pondré en él mi Espíritu y anunciará el derecho a las naciones. No se meterá en disputas, no lanzará gritos, no se oirá su voz en las plazas. No romperá la caña cascada ni apagará la mecha que todavía humea, hasta que haya conducido el derecho a la victoria. En su nombre las naciones pondrán su esperan7a" (12, 18-2l); "Decid a la hija de Sión: he aquí que tu rey viene a ti, humilde y montado en un asno y un pollino" $(21,5)$. Jesús es sobre todo el hijo del hombre, presente en el hombre anónimo que pasa hambre y sed, en el extranjero, en el que está desnudo, enfermo y prisionero (cfr. 25, 31-46). Por consiguiente hemos de comprender también las bienaventuranzas de Matco en su intención cristológica. Mateo las redactó teniendo ante la vista la persona y la acción de su Señor. Aquí se entremezclan la exhortación y la cristología.

Aparte del don, la introducción que pone Mateo al sermón de la montaña quiere destacar otro aspecto que al evangelista le parece importante y que desarrollará más la conclusión del sermón. La responsabilidad de la comunidad frente al mundo: por su obrar ha de ser luz del inundo y sal de la tierra $(5,13-16)$.

bienaventuranzas sobresale unas veces más un aspecto, otras veces otro". Por otro lado es J. Dupont, Les Béatitudes, París. 1971, vol. III, p. 667, el que subraya que en el fondo de lodas las bienaventuranzas late un solo tema: la justicia.

34. Hoffmann, Selig, p. 122.

35. Op. cil., p. 34.

36. Como señala Luz. op. cil., 1, pp. 294s., a propósito de la cuarta bienaventuranza. "los lugares paralelos judíos y helenísticos muesiran que 'lener hambre y sed' puede significar tanto 'anhelar' como 'eslorzarse por' algo. Por eso, nada se opone a la interpretación ética que la Iglesia antigua propuso casi exclusivamente. con buen criterio. De ese modo se mantiene la esinuctura veterotestamentaria de la 'justicia': justicia que es la conducta ordenada por Dios a su pueblo en virtud de la alianza. Su contenido aparece descrito más concretamente en 5, 20-48".

37. Op. cill., p. 65 . 


\section{Para Mateo}

los discipulos, es decir, los cristianos, son la luz del mundo cuando hacen brillar sus obras, al igual que la sal sólo es sal cuando sirve para salar. El indicativo "ustedes son la luz del mundo" es, pues, a la vez una exigencia que ha de realizarse mediante las obras" . 14):

Y se trata de una responsabilidad seria, pues en ello le va la vida (cfr. $7,13-$

Entren por la puerta estrecha; que es ancha la puerta y espacioso el camino que lleva a la perdición, y son muchos los que entran por él. Y es estrecha la puerta y angosto el camino que lleva a la vida, y son pocos los que lo encuentran.

\subsection{Parte principal del sermón de la montaña $(5,17$ - 7, 12)}

Como muy bien muestra la estructura que propongo. ${ }^{19}$, tanto la introducción (5, 17-20) como la conclusión $(7,12)$, que enmarcan el conjunto, muestran cuál es el punto de mira bajo el cual Mateo quiere que consideremos la parte central del sermón de la montaña. Por un lado, hay un supuesto claro: La ley y los profetas ( $c f r .5,17$ y 7,12 ) siguen teniendo toda su validez por lo que Jesús ha venido a cumplirla plenamente ( $c f r .5,17-19^{40}$ ).

Pero, por otro lado, Jesús, con su praxis y su enseñanza, nos da el criterio fundamental desde el cual hay que interpretar la ley aprendiendo a discernir, en caso de conflicto de valores, cómo dilucidar cuál es, en concreto, la voluntad de Dios. Pues asl evitaremos caer en una actitud "legalista"-11. Por ello, Mateo insis-

38. Luz, op. cir., I. pp. 313s.

39. Sigo en lo fundamental a Luz; cfr. supra, n. 22.

40. Mi agregó este preámbulo a las antítesis "para garantizar que no se pudieran interpretar en ningún caso por la vía antinómica, como ruptura con la herencia de lsrael. La comunidad mateana habra sufrido la dolorose ruptura con la sinagoga y se encontró fuera del judaísmo. En esta situación. Mateo hubo de reivindicar programáticamente el Antiguo Testamento en lo referente al ser personal de Dios, el Padre de Jesús. Las citas de reflexión significan la reivindicación programática de los vaticinios: y nuestro pasaje, la reivindicación programálica de la ley" (Luz, op. cil., I , p. 338).

41. Como nota Sicre, "El sermón del monte (11): la actitud ante la ley". Proyección 39 (1992) pp. 5-6: "Al legalismo se puede llegar por dos caminos muy parecidos:

"a) Buscando seguridad humana": una persona inmadura, con miedo a correr riesgos. prefiere que le indiquen en cada momento lo que debe hacer. Cuantas más normas, mejor, porque asI no se siente insegura.

"b) Buscando seguridad religiosa". Estas personas conciben la salvación como algo que se gana a pulso. a base de esfuerzo, cumpliendo en todo momento la voluntad de Dios. Y esta voluntad de Dios no la conciben como una actitud global en la vida. sino concretada en una serie de actos. Cuantas más normas me dicten. mejor conoceré lo que Dios quiere y me resultará más fácil salvarme. 
te en que si no descubrimos y praclicamos este criterio fundamental, corremos el peligro de que "nuestra justicia" no sea mayor, es decir, más auténtica, que la de los escribas y fariseos (cfr. 5, 20). Dicho criterio lo formula claramente al final de la parte principal, desplazando el texto del lugar en el cual lo situaba la fuente $Q$, como lo muestra una comparación con el lugar que el texto ocupa en el "sermón del llano" en Lucas". Se trata de la denominada "regla de oro" que concreta el significado fundamental que tiene en Mateo el amor al prójimo, subrayando $-y$ es un añadido redaccional de Mateo- que en esta regla encontramos la quintaesencia de la voluntad de Dios (la ley y los profetas):

Así, pues, traten a los demás como quieran que ellos los traten a ustedes, porque en esto consisten la ley y los profelas (cfr. 7, 12; cfr. 22, 40).

Por ello se ha podido decir" que "el sermón de la montaña (5-7) anuncia la exigencia ilimitada del amor al prójimo".

Hasta qué punto es fundamental el amor al projino como criterio para poder interpretar adecuadamente la voluntad de Dios, concretada en la ley, lo muestran las antítesis que encontramos en 5, 21-48 y que son como un ejercicio práctico que desarrolla cómo quiere Mateo que comprendamos la moral cristiana. Pues, por un lado, con estas antítesis radicaliza Jesús el cumplimiento de la ley, de acuerdo con la tesis que había formulado en $5,17-19^{14}$. Y, por otro, muestra en

"En lo anterior hay cosas buenas y malas. Pero lo más grave es que la persona amante de las normas corre el peligro de quedarse en la letra de la ley, sin profundizar en su espíritu, que es más exigente. Por ejemplo, la ley manda no comer carne los viernes de cuaresma. Y se queda tranquila con cumplir la letra de la ley, pero no le preocupa comer langosta o gambas. (...)"

"Otro grave riesgo de la mentalidad legalista es que, con la ley en la mano, se puede machacar al prójimo y amargarle la existencia. Se critica al que no vive como uno cree conveniente, se lo condena interiormente, incluso se lo persigue".

42. En el "Trasfondo del sermón de la montaña" ( $f f r$ supra), en la cual he puesto en columnas paralelas los textos según se encuentran en $L c$ y en Mt puede verse como Mt ha desplazado de su lugar original el texto paralelo de Mt 7, 12: Lc 6, 31.

43. Zumstein, op. cit., p. 35.

44. “Cuál es la intención última de esta reinterpretación centrada en la radicalización? Lo mismo que en los relatos de controversias, se trata del amor. En efecto, exigir del hombre una obediencia radical, es pedirle que se abandone por completo a la reivindicación de Dios, pedirle que esté lotalmente disponible para él. Pero precisamente, como demuestran las seis antítesis, inscritas todas ellas en la segunda tabla del decálogo, esta apertura y esta disponibilidad se ejercen en favor del prójimo. Estamos tocando aquí un punto decisivo y su verificación, extendida a todo el evangelio, no harfa más que afianzar esta observación: el principio de la reinterprecación mateana de la ley, su sumario, por utilizar un término clásico. es el doble mandamiento del amor" (Zumstein, op. cit., p. 41). Luz. op. cit., J, p. 349, subraya que "la enmarcación de la serie antitélica entre la primera y la sexta antílesis pone de manifiesto que Mateo ve el núcleo del Antiguo Testamento en el amor. El amor es el cumplimiento y no la abolición de la ley y los profetas $(5,17)$. El precepto del amor no elimina los 'preceptos mínimos' (5, 18s), sino que los relativiza caso por caso. La ley y los profetas 'dependen' del precepto del amor $(22,40)$ ". 
qué sentido y con qué criterio hay que entender esta radicalización de la ley. Pues en ninguna de las seis antítesis radicaliza Jesús aspecto alguno de la ley cúltica o "de pureza" (15, 1-20 va en la misma línea). Sólo se radicalizan aquellos aspectos de la ley que tienen que ver con la relación con el prójimo, culminando todo ello en el amor a los enemigos, que es como la expresión palpable de la perfección divina a la que debe aspirar el cristiano (cfr. 5, 4348) ${ }^{43}$.

El resto del evangelio de Mateo -y sobre todo las discusiones con los adversarios a propósito del cumplimiento o no de la ley por parte de Jesús (cfr. $9,1-17 ; 12,1-14 ; 15,1-20 ; c f r$. también 9, 20-22)- confirma esta constatación que hemos hecho a propósito del sermón de la montaña. Como señala Zumstein ${ }^{46}$

Los relatos de controversias abren de esta forma una brecha: ciertamente, la ley es válida en su integridad, pero lo es con tal que sea conforme con la voluntad original de Dios; a condición de que sea considerada en función de su intención central que es el amor. Para formularlo de manera paradójica: a los ojos del Cristo mateano, es legítimo y hasta necesario transgredir la Torá, en nombre de la Torá, ya que el amor está sobre la letra, la verdadera fidelidad sobre la obediencia legalista.

En cuanto a las obras de piedad clásicas en el judaísmo (la limosna, la oración y el ayuno: $c f r .6,2-18)^{47}$, éstas quedan subsumidas bajo el concepto mateano de justicia:

Guárdense de hacer el bien (la palabra que emplea Mateo aquí es dikaiosynê) sólo para que los vean los hombres, porque entonces el Padre celestial no los recompensará $(6,1)$.

Tanto en ellas como en las recomendaciones de no poner el corazón en las riquezas $(6,19-24)$, de no agobiarse $(6,25-34)^{44}$, de no juzgar $(7,1-5)$, de no

45. Luz, op. cir. 1, p. 265, indica, a proposito de las exigencias del sermón de la montaña, que "no son cláusulas legales, sino exigencias ideales que ilusiran a modo de ejemplos la radicalidad de la obediencia que Dios exige. La ejemplaridad implica siempre la libertad para inventar nuevos ejemplos. No hay, pues, para Mateo una definición univoca de la conducta cristiana ni una permisión total en el sentido del 'dilige et fac quod vis'.

46. Op. cit., Pp. $38 \mathrm{~s}$.

47. Lo mismo puede decirse para los valores que configuran la identidad cristiana y que encontramos en 6, 19-7, 11 , pues también ellos quedan subsumidos bajo el concepto de justicia que encontramos en 6, 1 .

48. Porque "lo importante es 'el reino de Dios y su justicia', es decir, esa sociedad perfecta que debemos anticipar los cristianos en la medida de lo posible. Dentro de ella no pueden tener cabida las desigualdades hirientes ni las injusticias, el que hermanos nuestros mueran de hambre o pasen terribles necesidades inientras a otros les sobran multitud de bienes. Pero, si nos preocupamos sólo de la comida y del vestido, de las necesidades primarias, renunciaremos a buscar ese reinado de Dios" 
dar lo "santo" a los "perros" $(7,6)^{\text {t" }}$ y de confiar plenamente en la oración $(7,7-$ 11), Mateo insiste, por el contexto, en la actitud interior que dehe caracterizar la moral cristiana, que no es una moral de leyes o normas externas, sino que brota de una experiencia honda de la gratuidad del amor de Dios que en Jesús de Nazaret ha empezado a hacer presente su reinado en este mundo. Por eso, Mateo siltúa el fragmento sobre el don de Dios como respuesta a la oración confiada al rinal de la parte principal del sermón de la montaña (y no simplemente porque aparece el verbo "dar" tanto en el v. 6 como en el v. $7^{49}$ ). Pues a la luz de la redacción mateana de Mateo 19, 16-17, las "cosas bucnas" que da Dios según 7. 11, se refieren, probablemente, según Hoffmann", a la comprensión adecuada de la ley. Con ello

se hace caer en la cuenta a los discípulos, al final de la interpretación de la ley, que la comprensión que permile interpretar bien la ley es un don de Dios, que ellos no sólo pueden sino también deben pedir con toda confian$\mathrm{za}^{\mathrm{s}}$.

Por ello también, lodo esla fragmento del sermón de la montaña, que va Jesde 5, 17 hasla 7, 12. gira en torno al tema central de la oración"': 6, 5-15. Y no es casual que el "Padre nuestro" constituya el corazón mismo de este frag-

(Sicre "El sermón del monte (IV): La actitud ante el dinero y el projimo", Proyección 39 (1992) p. 197. "En resumen. todo el mensaje de Jesús se sintetiza en dos principios básicos: I) el valor relativo de los bienes (errenos en comparación con el valor supremo de Dios y de su reinado; 2) el valor absoluto de la persona necesitada, que exige de nosotros una postura de generosidad" (ibid., p. 198).

49. El texto resulta un poco enigmático, como notan todos los comentaristas del mismo. En él "se han unido probablemente dos refranes que originariamente eran independientes" (P. Hoffmann, "Der ungeteilte Dienst. Die Auslegung der Bergpredigt V (Mt 6. 1-7, 27)", Bibel und Leben 11 (1970) p. 97). Según el mismo autor (ibid.), la advertencia "no den lo santo a los perros" hace referencia a una norma judía sobre los sacrificios, según la cual estaba prohibido dar a los peros la carne de los sacrificios que ya no se podía utilizar con este fin. $Y$ el segundo refrán tendría un sentido semejante: no dar las perlas a los cerdos significa que no hay que profanarlas. Hoffmann señala que una interpretación bien lograda es llamada una "perla" en la tradición rablnica. Por ello piensa (ibid.. pp. 97-98) que "sanıo" y "perla" se refiere en Mt 7, 6 a la enseñanza de Jesús que hay que evitar que sea profanada. $Y$ no se puede excluir que la prohibición vaya dirigida contra los herejes, pues en la tradición tardía del cristianismo primitivo los herejes son denominados "perros" (cfr. Flp 3, 2; 2P 2, 22; Ignacio, carta a los Efesios 7, 1) y, en ocasiones, comparados con "cerdos" (2P 2. 22; Barn 10, 1-3; EvTom 93; EvFlp 119).

50. Contra H. Th. Wrege, Die überlieferung der Bergpredigt, Tubinga, 1968, p. 107 (cilado por Hoffmann Ungeteilie Dienst 99).

51. Ibid., p. 99. Según él, en 19. 16-17 "aparece tan claramente la conexión enlre lo 'bueno' y los 'mandamientos', como la trabazón de lo bueno con el único que es bueno, es decir, con Dios, que es quien da los mandamientos".

52. HofJmann, ibid., p. 100.

53. Ver la presentación de la estructura del sermón de la monlaña. 
mento. Pues la venida del reino, de la cual quiere ser signo en el mundo la comunidad que esı́́ llamada a vivir el sermón de la montaña, sólo es posible a partir del don previo de Dios. Por eso se debe pedir en la oración: "venga tu reino" (6, 10).

\section{Conclusión del sermón de la montaîa (7, 13 - 27)}

La conclusión del sermón de la montaña confirma lo que hemos visto al comienzo sobre lo que preocupa realmente a Mateo a propósito de su comunidad: que a un grupo importante le falta precisamente aquello que muestra que uno es discípulo de Jesús. Me refiero a los "frutos" ( $c f r .7,15-20$ ) que, en Mateo. se identifican con cumplir la voluntad de Dios, que queda condensada, como en su quintaesencia, en el amor al prójimo (cfr. 7, 12). Por esto Mateo, al final, insiste tanto en los peligros a los cuales se expone la comunidad por culpa de los falsos profetas que descuidan cumplir el núcleo de la ley (cfr. 7, 21-23) y en la importancia de la praxis cristiana (cfr. 7, 24-27).

\section{1. ¿Cómo podemos interpetar hoy el sermón de la montaña?}

Luis Fernando Garcia-Viana"s responde así:

Según la interpretación de Mateo, el sermón de la montaña no puede ser ni una nueva ley ni una enumeración de principios abstractos. Por el contrario, se trala del anuncio definitivo de la voluntad de Dios hecha por Jesús como consecuencia directa de la llegada del reino. De hecho, el discurso se inicia con la proclamación solemne de las bienaventuranzas, que, en la versión de Mateo, asumen una doble dimensión y tarea: buena noticia para los pobres y programa de vida para los humildes de corazón, que han aceptado el anuncio del reino proclamado por Jesús y se han decidido a seguirle. En la perspectiva del reino y del seguimiento, las exigencias éticas del sermón de la montaña reciben su dinamismo escatológico, su verdadera radicalidad. La revelación de la voluntad de Dios se dirige al hombre o a la mujer que han acogido la buena noticia de su liberación. Son ahora libres para obedecer al único Señor y libres para amar de un modo activo e incondicionado al prójimo, eliminando, en este último caso, las posibles discriminaciones que todavía existían en la situación histórica del evangelio de Mateo.

En este sentido podemos decir que el sermón de la montaña es una "buena nolicia" en cuanto no es una "norma moral externa", irrealizable para nosotros, sino una una "llamada a la libertad"ss de los hijos e hijas de Dios que, por don de Dios, realizan el encargo que el Padre les ha confiado: mostrar a todo el mundo que el estilo de vida de Jesús, cuando no se realiza sólo a nivel personal.

54. "El sermón de la montaña como camino para una justicia más grande", Reseña Bíblica. No 2 (1994) p. 36.

55. Vale la pena leer el sugerente libro de E. Käsemann, La llamada de la libertad. Salamanca, 1974. 
sino como comunidad, como "pueblo de Dios", es fuente de auténtica felicidad y camino alternativo para superar la injusticia que crucifica a la mayor parte de la humanidad. Pues como nola Camacho ${ }^{36}$

lo que, en delinitiva, pretenden los que con sus opciones, actitudes y comportamiento están haciendo presente en la historia el reinado de Dios, es que esa experiencia de libertad, fraternidad e igualdad, esa felicidad que ellos están disfrutando, sca también compartida por la humanidad entera. Y, para ello. no bastan los buenos deseos ni los nobles propósitos, es necesario el empeño diario por ir abriendo en la historia los caminos del reino, por ir despejando los obstáculos que impiden su implantación y fomentando todo lo que contribuye a hacerlo realidad.

La misión de los que tienen a Dios por rey es trabajar con ahinco por la maduración de la humanidad en una doble dirección: la de su liberación y la de su desarrollo a través del amor. Su tarea primordial consistirá, pues, en ir haciendo hombres libres y promoviendo unas relaciones personales acordes con la dignidad humana. Sólo así se conseguirá la transformación de la sociedad. Pero, para llevar a cabo esa tarea, ellos mismos han de ser libres y tener talla humana, de lo contrario no podrán realizarla.

Por eso el sermón de la monlaña es también una llamada a la conversión y una explicitación "de lo que liene que ser una vida "convertida' "s7. Pues, como señala Camacho",

los que están a favor de los oprimidos y en contra de los opresores, si quieren llegar a ser personas cabales y contribuir a la liberación de los oprimidos y a la denuncia de los opresores, han de optar radicalmente por la justicia, que constituye, según las bienaventuranzas, la condición de posibilidad de la sociedad nueva o reino de Dios, $y$ han de hacer real y efectivo un modo de vida distinto y alternativo al propuesto por los que dirigen, controlan, manipulan la sociedad injusta. Tcológicamente hablando, ese modo de vida es el propio de los que están en sintonfa con Dios, de los movidos por su Espiritu, o, si se prefiere, por usar la teminología paulina, de los hombres

56. Op. cir., p. 134.

57. Lambrech, op. cir., p. 209. Por ello añade: "La entrada en el reino de los cielos va ligada a una condición precisa: una justicia más abundante que la de los escribas y fariseos (cfr. 5, 20), hacer la voluntad del Padre celestial (cfr. 7, 21-23). Las bicnaventuranzas. como hemos visto, evocan las actitudes exigidas por el reino, por las cuales los cristianos se convienten en luz del mundo (5, 3-16); las antítesis concretan aún más cuál es la voluntad propia del Padre $(5,17-48)$; no se trata de practicar la justicia mayor para llamar la atención de los hombres $(6,1-18)$; nuestra primera preocupación debe tener siempre como objeto el reino de Dios y su justicia, y no el alimento y el vestido (6, 19-7, 12); se trata, en fin, no sólo de conocer la voluntad del Padre, sino también de hacerla $(7,12-27)$. Es evidente: la enseñanza de Jesús en el sermón de la montaña es al mismo tiempo invitación, advertencia y exhortación".

58. Op. cis., p. 133. 
nuevos, capaces de ir creando una nueva sociedad.

La ética de estos hombres nuevos, según las bienaventuranzas, en particular las de Mateo, puede definirse como la ética de la austeridad solidaria. Lo que las bienaventuranzas, e indirectamente también las malaventuranzas lucanas, proponen para hacer presente en el mundo el reinado de Dios es un modo de vida humano que no haga del dinero el centro de la existencia, que no busque acaparar, dominar o destacar, que se plantee la vida con sencillez, sin afán de lucro o de lujos, que no traicione, en aras del reconocimiento social, los principios fundamentales del mensaje de Jesús y que asuma como valor supremo la solidaridad.

En este sentido, el sermón de la montaña -y su moral- es todo lo contrario de lo que D. Bonhoeffer denominaba una "gracia barata", que él definía así:

La gracia barata es la predicación del perdón sin arrepentimiento, el bautismo sin disciplina eclesiástica, la eucaristía sin confesión de los pecados, la absolución sin confesión personal. La gracia barata es la gracia sin seguimiento de Cristo, la gracia sin cruz, la gracia sin Jesucristo vivo y encamado. La gracia cara... es la llamada de Jesucristo, que hace que el discípulo abandone sus redes y lo siga... Es cara, porque le cuesta al hombre la vida; es gracia porque le regala la vida".

Por eso las personas que se dejan configurar por el talante del sermón de la montaña pueden afirmar de sí mismas, lo que Mons. Casaldáliga dice en su poesía "En éxodo":

Al acecho del Reino diferente, Voy amando las cosas y la gente, ciudadano de todo y extranjero.

Y me llama Tu paz como un abismo mientras cruzo las sombras, guerrillero del Mundo, de la Iglesia y de mí mismo.

Evidentemente, lo que Jesús propone en el sermón de la montaña es una utopía. Pero, como señala Mons. Casaldáliga, se trata de "la utopía del evangelio. El hombre nuevo no vive sólo de pan; vive de pan y de utopía. Sólo hombres nuevos pueden hacer el mundo nuevo"so.

59. El precio de la gracia. pp. 18-20.

60. Al acecho del reino, Madrid. 1989, p. 40. 